\title{
Enabling transformative value creation through online weight loss services
}

\author{
Heini Taiminen, Kimmo Taiminen and Fuha Munnukka \\ School of Business and Economics, Jyväskylä University, Jyväskylä, Finland
}

\begin{abstract}
Purpose - This study aims to understand how online weight loss services could help customers achieve a durable change. The particular focus is on exploring the roles of value co-creation and well-being outcomes in reinforcing the transformative value potential, which is argued to be realized as customers' intentions to continue a healthier lifestyle after the service period has ended.

Design/methodology/approach - Data was collected from the participants of an online weight loss service $(n=498)$, and a conceptual research model was tested using structural equation modelling.

Findings - The results imply that compliance with the guidelines and social support are two value co-creation activities that can influence the wellbeing outcomes of transformative services (i.e. perceived behavioral control and satisfaction with one's achievements). These well-being outcomes help attain the transformative value potential of online weight loss services. However, the actual weight loss affected the transformative value potential only through customers' satisfaction with their achievements as a subjective well-being outcome.

Originality/value - This study provides insight into the transformative value potential of services in the weight loss context. This study contributes to the transformative service research by focusing on the role of online services in reinforcing a durable change through the co-creation of value and improvements in customers' well-being.
\end{abstract}

Keywords Well-being, Co-creation, Health services, Self-service technology, Peer-to-peer, Transformative service, Transformative value, Weight loss, Behaviour maintenance, Social support

Paper type Research paper

\section{Introduction}

Overweightness and obesity constitute a common risk for many chronic diseases in the Western world. In the fight against overweightness, digital delivery offers easy access to low-threshold self-services to people who are motivated to lose weight and change their behavior to live more healthily (Kozak et al., 2017; Hutchesson et al., 2015). These services act as a part of the transformative service landscape, which enables "creating uplifting changes and improvements in the well-being of consumer entities" (Anderson et al., 2011 p. 3). Weight loss services most often focus on helping customers lose weight (e.g. Napolitano et al., 2013; Turner-McGrievy and Tate, 2011). While weight loss improves the physical well-being of individuals, it does not necessarily generate an uplifting change. In fact, people who successfully lose weight often regain it relatively quickly (Montani et al., 2015). Therefore, the sole focus on weight loss is inadequate from the transformative service perspective.

In addition to weight loss results, this paper highlights the important role of online weight loss services in helping customers generate a durable change in their life (e.g. Blocker and Barrios, 2015; Previte and Robertson, 2019). To successfully achieve this change, online weight loss services should aim to nurture their transformative value creation potential. Transformative value is "a

The current issue and full text archive of this journal is available on Emerald Insight at: https://www.emerald.com/insight/0887-6045.htm

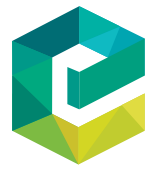

Journal of Services Marketing

34/6 (2020) 797-808

Emerald Publishing Limited [ISSN 0887-6045]

[DOI 10.1108/JSM-05-2019-0191] social dimension of value creation that generates uplifting change for greater well-being among individuals" (Blocker and Barrios 2015 , p. 265). As argued in this study, the transformative value potential of services reflects the capability of a service to reinforce a durable change in its customers. The realization of this potential manifests not only as improved well-being but as customers' intention to continue to maintain the improved well-being after the service process has ended. In the context of this study, the transformative value potential focuses on customers' intentions to continue to live a healthier lifestyle.

This study scrutinizes the service elements that enable online weight loss services to nurture their transformational value potential. To address this issue, the value co-creation perspective based on the service-dominant logic (Vargo and Lusch, 2004; 2008) is applied. Thus, we provide empirical evidence illustrating how two value co-creation activities commonly utilized by traditional online weight loss services (i.e. "compliance with eating and exercising guidelines" and "social support"), the well-being

(C) Heini Taiminen, Kimmo Taiminen and Juha Munnukka. Published by Emerald Publishing Limited. This article is published under the Creative Commons Attribution (CC BY 4.0) license. Anyone may reproduce, distribute, translate and create derivative works of this article (for both commercial and non-commercial purposes), subject to full attribution to the original publication and authors. The full terms of this license may be seen at http://creativecommons.org/licences/by/4.0/legalcode

This work was supported by Emil Aaltonen Foundation. We gratefully thank the foundations for their support.

Received 10 May 2019

Revised 17 September 2019

23 December 2019

27 March 2020

Accepted 3 May 2020 
outcomes of such services (i.e. "perceived behavioral control" [PBC] and "satisfaction with one's achievements") and transformative value potential are interlinked.

Building upon the health psychology literature (e.g. Baldwin et al., 2006; Rothman et al., 2004) and existing discussion regarding online weight loss programs (e.g. Ballantine and Stephenson, 2011; Hwang et al., 2010; Hwang et al., 2011), we respond to the need for an interdisciplinary focus in transformative service research (TSR) (Anderson and Ostrom, 2015). Specifically, this study contributes to the TSR literature in two ways. First, following Mulder et al. (2015) and Blocker and Barrios (2015), this study focuses on durable change instead of temporal improvements in well-being, thereby responding to the call for more research concerning the "sustainability of transformation over time" (Previte and Robertson 2019, p. 672). Second, the results advance our understanding of the transformative potential of services and their effective design (e.g. Rosenbaum et al., 2011; Anderson et al., 2013) by revealing the transformative value potential of two traditional service elements, namely, weight loss guidelines and social support.

This paper is structured as follows. First, a theoretical discussion is presented to address the roles of value co-creation, well-being outcomes and transformative value potential in the context of online weight loss services. Second, the conceptual model and hypotheses are provided. Third, the data collection method is presented, and the results are analyzed. Finally, the results are discussed in relation to theory, and managerial implications are offered.

\section{Theoretical background}

\section{Value co-creation in online weight loss services}

Improving individual and collective well-being is an essential aim of TSR (Anderson et al., 2013). To explore the various roles of transformative services, the TSR literature has commonly adopted value co-creation and service-dominant logic (S-D logic) as the theoretical foundation (Kuppelwieser and Finsterwalder, 2016; Previte and Robertson, 2019) and argued that service is an interactive process central to improving well-being. Value co-creation represents a key aspect of S-D logic. Specifically, S-D logic posits that service occurs in value co-creation processes in which different actors interact and integrate their operant resources (skills and knowledge) and operand resources (goods and materials) for their own benefit or the benefit of others in the service network (Vargo and Lusch $2004 ; 2008)$. In an integrated view of S-D logic and TSR, customers create well-being through service activities, and service providers aim to facilitate customer well-being by making value propositions (Kuppelwieser and Finsterwalder, 2016).

Value propositions can be a fundamental reason explaining why customers choose to engage with a particular service (Chandler and Lusch, 2015). To fulfil the value proposition, online weight loss services typically provide different instructions and guidelines to help customers lose weight. While some services in the industry focus solely on providing diet instructions, most successful services integrate regular healthy eating and exercising guidelines (Dombrowski et al., 2014). The provided guidelines act as a resource in value co- creation, especially when customers comply with the service provider's guidelines. This process requires customers to take responsibility and actively contribute to the service process (Chan et al., 2010; Dellande et al., 2004). Customers need to assume control and comply with the guidelines consistently in their everyday life. Customers also need to adapt their behavior regularly to correspond to the guidelines to boost their weight loss.

Social support represents another potential resource for value co-creation in online weight loss services (Parkinson et al., 2017). Based on House (1981), social support consists of informational, instrumental, emotional, and appraisal dimensions. The informational dimension relates to the guidance or advice provided by others (e.g. "talking with a dieter about calorie content"). Instrumental support refers to tangible aid in terms of resources, such as money, materials or labor (e.g. "walking with another person"). Emotional and appraisal support are very similar to each other. Emotional support consists of aspects, such as encouragement, esteem, affect and concern, provided to the social support recipient (e.g. "a pep talk"), while appraisal support relates to the provision of feedback and affirmation (e.g. "telling the dieter he/she is doing a great job"). In general, emotional and informational support are acknowledged as the most common social support types. In an exploratory study of a public online weight loss community, Hwang et al. (2010) found that encouragement, motivation, information, and shared experiences among the members are the contributing elements of social support. Furthermore, Ballantine and Stephenson (2011) examined Weight Watchers' Facebook page and concluded that the Facebook page acts as a platform for emotional and informational social support.

\section{Well-being outcomes of online weight loss services} Improved well-being is the outcome value of transformative services (Anderson et al., 2013). Well-being refers to customers' subjective perception (Sharma et al., 2017). Therefore, transformative value creation requires customers to recognize their improved well-being state (Blocker and Barrios, 2015). Perceptions of one's well-being are either hedonic or eudaimonic in nature. Hedonic well-being arises from pleasurable experiences during transformative value creation (Sharma et al., 2017) or as an outcome of the service process (Blocker and Barrios, 2015). Hedonic well-being occurs as a customer's state of happiness, pleasure and satisfaction (Anderson et al., 2013). In contrast, eudaimonic well-being arises from improvements in individuals' competence, self-esteem, optimism, etc. (Deci and Ryan, 2000). This state is characterized by human flourishing (Diener et al., 2010) and self-actualization (Deci and Ryan, 2000). Eudaimonic well-being is primarily important for transformative value creation because eudaimonic well-being empowers customers to maintain their improved well-being in the future (Blocker and Barrios, 2015).

Sharma et al. (2017) noted that self-efficacy is a key eudaimonic well-being outcome in health service context. Selfefficacy refers to a person's confidence in his/her abilities to perform a desired behavior (Bandura 1986). According to Sharma et al. (2017, p. 405), self-efficacy is enabled by customer perceptions of improved competence ("i.e. confidence to achieve their potential/goals") and autonomy 
(i.e. "sense of control over their efforts") as a result of customer-provider value co-creation. Notably, self-efficacy is also an important factor for successful weight loss (Linde et al., 2006) and maintaining beneficial behaviors (Keats and CulosReed, 2009). Instead of self-efficacy, this study focuses on the closely related but more extensive concept of PBC [1]. PBC covers individuals' perceptions of their ability to perform the desired behavior and beliefs regarding their level of control over performing the behavior (Ajzen, 2002). PBC builds upon individuals' perceptions of their past and considers their futureorientation (Ajzen, 1991). Therefore, PBC is consistent with the transformative service research focus on improving wellbeing and creating persistent, uplifting, durable change.

In this study, we also focus on another well-being outcome, namely, satisfaction with one's achievements. Customers' sensations of accomplishment are acknowledged as an eudaimonic well-being outcome of transformative services (Sharma et al., 2017). Such accomplishments become satisfactory evaluations when customers interpret the particular achievements as successes or failures (Bagozzi and Dholakia, 1999; Fishbach et al., 2004). In the weight loss context, satisfaction is especially linked to evaluations of one's weight loss process and its results (Finch et al., 2005; Rothman, 2000). Therefore, satisfaction with achievements mirrors customers' evaluations of whether their well-being is improved because of value co-creation in online weight loss services.

\section{Transformative value potential of weight loss services}

The previous discussion regarding the well-being outcomes of weight loss services reflects improvement in individual wellbeing because of the service process. At best, transformative services are able to facilitate a durable change that lasts after the service period (Mulder et al., 2015). Similarly, Blocker and Barrios (2015, p. 277) stated that customers experience an uplifting change when they feel that "it is hard to imagine living under the previous state". Thus, true transformation indicates that the customer will abandon his/her old habits and has a strong intent to continue to follow the newly learned behavior.

However, in the weight loss context, it is very common for those who lose weight to regain it (MacLean et al., 2015;
Montani et al., 2015). Thus, to foster transformative value creation and reinforce a durable change, online weight loss services should help customers maintain a healthier lifestyle. Online weight loss services seldom play an ongoing role in customers' lives. Therefore, these services most often only carry the potential to help customers strive for a durable, healthy lifestyle. In this process, customers' intentions to behave healthily in the future have a major impact on achieving a successful change (e.g. Ajzen and Fishbein, 1980; Bandura 2004; Rhodes and de Bruijn, 2013). Consequently, we argue that the transformational value potential of online weight loss services is realized when the customers intend to continue to maintain a healthier lifestyle after the service period, mirroring the potential of transformative services to encourage their customers to realize an uplifting change that extends beyond a temporarily improved well-being.

\section{Hypotheses development}

To successfully promote a durable change and help customers maintain a healthy lifestyle, weight loss services should shift their sole focus from weight loss results to well-being outcomes and value co-creation activities fostering transformative value creation. This study aims to understand the roles of social support and compliance with guidelines, which are two value co-creation activities, in fostering PBC and satisfaction with achievements as the well-being outcomes of services. Figure 1 illustrates this logic and presents the conceptual research model. Subsequently, the hypotheses related to each relationship in the research model are provided.

\section{Determinants of the transformative value potential of services}

PBC is known to play a major role in behavioral change processes and determining individuals' ability to maintain change (DiClemente et al., 1985). Self-efficacy and, thus, PBC are considered critical, especially during the early phases of behavioral maintenance (Rothman, 2000; Linde et al., 2006) because self-efficacy and PBC are based on the learning process and relate to utilizing self-regulatory skills (such as planning), which help individuals maintain behavior (such as regular

\section{Figure 1 Conceptual model}

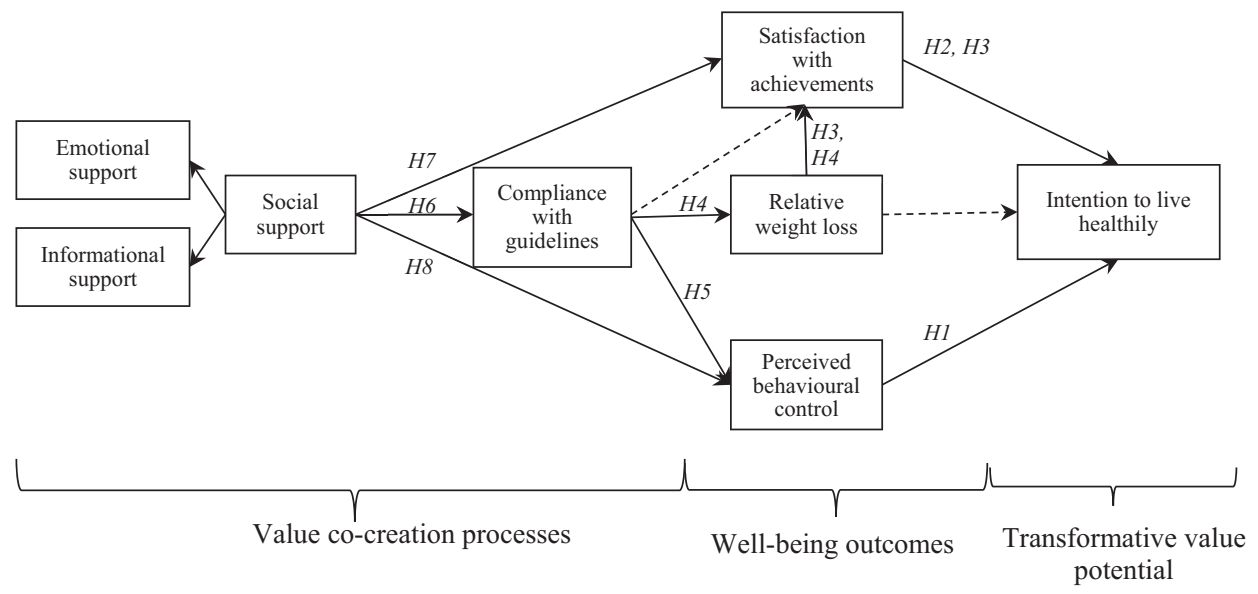


exercising) (Fleig et al., 2011). Based on this rationale, this study hypothesizes the following:

H1. PBC has a positive effect on the intention to live healthily.

According to Rothman (2000, p. 66), "people will maintain a change in behavior only if they are satisfied with what they have accomplished". Indeed, it has been found that those who are satisfied with their weight loss results are more likely to maintain the achieved weight (Finch et al., 2005). Baldwin et al. (2006) focused on the roles of satisfaction with their achievement and self-efficacy in the context of programs aiming to help individuals quit smoking. Their results revealed that customers' decision to carry on a non-smoking lifestyle was primarily guided by their satisfaction with their achievement when the non-smoking behavior had been continued for some time after the program has ended. Reflecting upon these findings, we expect that satisfaction with achievements affects the intention to maintain a healthy lifestyle. In light of the above, we hypothesize the following:

H2. Satisfaction with achievements has a positive effect on the intention to live healthily.

The amount of weight loss is an important factor for success in online weight loss services (e.g. Napolitano et al., 2013; Turner-McGrievy and Tate, 2011). While weight loss mirrors the improved physical well-being of individuals, it lacks the evaluative orientation important for transformative value creation (Blocker and Barrios, 2015). Similarly, tentative evidence suggests that the amount of weight loss is insufficient for accurately predicting behavior maintenance (Baldwin et al., 2006; MacLean et al., 2015). Thus, the amount of weight loss alone does not seem to encourage durable change, which is important for transformative value creation (Blocker and Barrios, 2015). In this study, we posit that to influence the intention to maintain behavior, the amount of weight loss requires customers to experience improvements in their subjective well-being. Hence, customers must first evaluate the weight loss process, which allows them to become satisfied with their achievements (Baldwin et al., 2009). Hence, this paper argues that weight loss embodies an indirect transformative value potential through satisfaction with one's achievements. Therefore, we suggest the following hypothesis:

H3. The positive effect of weight loss on the intention to live healthily is mediated by satisfaction with achievement.

\section{Co-creation activities contributing to the well-being outcomes of services}

Consistent with the existing TSR literature (Blocker and Barrios, 2015; Abney et al., 2017; Sharma et al., 2017), this study adopts a value co-creation perspective to understand how services can shape well-being. In particular, we address the importance of compliance with guidelines and social support in co-creating well-being outcomes in the context of weight loss services. Reflecting upon the S-D logic (Vargo and Lusch, 2004; 2008), guidelines represent an application of the service provider's skills and knowledge for the benefit of the customer. When customers successfully comply with guidelines, their weight loss should be boosted (Dellande et al., 2004). The successful utilization (i.e. weight loss) of service providers' resources (i.e. guidelines) should further induce satisfaction with achievements, leading to the following hypothesis:

H4. Relative weight loss mediates the relationship between complying with guidelines and satisfaction with achievements.

Furthermore, prior evidence suggests that self-efficacy is formed through information that is conveyed actively, vicariously, socially and physiologically (Bandura, 1986, 1993). As a logical reflection upon the discussion regarding selfefficacy and PBC (Ajzen, 2002; Deci and Ryan, 2000), customers who integrate their resources and successfully utilize service providers' skills and knowledge (i.e. comply with guidelines) should develop competence and gain confidence in their behavior (see also Sharma et al., 2017). Therefore, the following hypothesis is proposed:

\section{H5. Complying with guidelines has a positive effect on PBC.}

In the weight loss service context, value co-creation also occurs between peer customers, especially in the form of social support. Previous research has indicated that social support has a positive impact on the adoption of a new behavior and controlling one's weight (e.g. Elfhag and Rössner, 2005; Gorin et al., 2007; Wing and Jeffery, 1999) because social support helps customers learn more about weight loss (i.e. information support) (Hwang et al., 2010) and better manage their weight loss attempt (Hether et al., 2014). Similarly, the encouragement of others (i.e. emotional support) helps customers cope with their weight loss attempt (Hwang et al., 2010). Thus, the related hypothesis is as follows:

H6. Perceived social support has a positive effect on complying with guidelines.

Social support can also act as a motivator helping customers succeed in their weight loss attempt (Hwang et al., 2010). For example, Winett et al. (2007) found that compared to a control group, receiving social support increased individuals' physical activity and healthy eating habits. When social support groups help customers perform better, social support should increase satisfaction with achievements. However, customers may also encounter disappointments during the weight loss process. In this case, the encouragement and acceptance from others (i.e. emotional support) may help customers cope with the disappointments (Hwang et al., 2010) and manage their stress (Uchino et al., 1999). Thus, customers who receive social support may evaluate their achievements as more satisfactory. Therefore, we hypothesize the following:

H7. Perceived social support has a positive effect on satisfaction with achievements.

Finally, social support helps customers learn from peers who underwent a similar experience of losing weight (Gorin et al., 2007; Hwang et al., 2010). Obtaining information regarding how peers have lost weight may increase customers' abilities to perform similar behaviors. Thus, learning from others empowers customers to become competent in implementing a 
healthier lifestyle (Willis, 2014). Moreover, encouragement from others has been found to improve health-related selfefficacy (Oh et al., 2013; Parkinson et al., 2019). Thus, emotional support may strengthen consumers' confidence in their skills and increase their belief that they have full control over fulfilling their aims, such as living a healthier lifestyle. Therefore, the final hypothesis is as follows:

H8. Perceived social support has a positive effect on PBC.

\section{Methodology}

Data collection

The data was collected from participants of a six-week online weight loss program using an online survey. The aim of the program was to assist the participants to lose weight and adopt a healthier lifestyle. The program was designed especially for overweight people and offered specific nutrition and exercise guidelines. Each week, the participants received slightly modified diet instructions based on healthy eating using basic food ingredients. The instructions were delivered via the service provider's website, which included instruction videos, recipes and workout instructions. Furthermore, each week, the company posted an encouraging video to inspire the participants to continue the program. In addition to these service provider's core resources, the weight loss service program included a closed anonymous online forum and a closed Facebook group specific to the participants of this program, where the participants could interact and co-create social support with others.

The survey link was sent to the program participants immediately after the intensive program period. In total, 519 responses were received, yielding an effective response rate of $69 \%$ (the share of completed questionnaires of the opened survey links). Of the responses, 12 were excluded because body mass index (BMI) information was missing, and 9 were excluded because they were identified as outliers based on the Mahalanobis distance measures. The final sample included 498 completed questionnaires.

Most respondents were women (94.9\%) who lived in a city $(67.1 \%)$, lived with someone $(85.4 \%)$ and were employed (68.4\%). On average, $4.98 \mathrm{~kg}$ (sd. 2.76) of weight were lost, and the BMI decreased by 1.78 units during the six-week period (Table 1).

\section{Measures and analysis}

The scales used to measure each construct were adapted from the previous literature with minor modifications to better fit the context of the present study. The measurement scales consisted of 28 items that involved six constructs (Table 2). The intention to live healthily and PBC were measured with fouritem scales adapted from Povey et al. (2000), informational support was measured with a six-item scale, and emotional support was measured with a seven-item scale adapted from Ballantine and Stephenson (2011). The three-item scale used to measure compliance with guidelines was adapted from Hether et al. (2014). The relative weight loss was measured by calculating the weight loss percentage from the self-reported data of the participants (height and weight at the beginning and end of the program). The relative weight loss was considered a
Table 1 Background information

\begin{tabular}{llr}
\hline Demographic & Value & Frequency (\%) \\
\hline Gender & Female & $465(94.9)$ \\
& Male & $25(5.1)$ \\
Age & Missing & $8(1.6)$ \\
& $15-19$ & $14(2.9)$ \\
& $20-29$ & $139(28.4)$ \\
& $30-39$ & $181(37.0)$ \\
& $40-49$ & $103(21.1)$ \\
Lives & $50-59$ & $37(7.8)$ \\
& $60-69$ & $13(2.7)$ \\
Lives & In the countryside & $161(32.9)$ \\
& In the city & $329(67.1)$ \\
Occupation & Missing & $8(1.6)$ \\
& Alone & $72(14.6)$ \\
& With someone & $421(85.4)$ \\
& Missing & $5(1.0)$ \\
Body mass index & Student & $45(9.1)$ \\
& Unemployed & $21(4.2)$ \\
& On family leave & $72(14.5)$ \\
& Retired & $5(1.0)$ \\
& Working & $340(68.4)$ \\
& Something else & $14(2.8)$ \\
& Missing & $1(0.0)$ \\
& BMl before & 29.07 \\
& & 27.29 \\
\hline
\end{tabular}

more accurate measure of the program's success than the absolute weight loss, which accounts for differences in the participants' baseline weights (see, e.g. Baldwin et al., 2009). Additionally, the satisfaction with achievements scale was used to reflect the respondents' evaluation of the weight loss program's outcomes. This measure was constructed based on studies conducted by Bagozzi and Dholakia (1999) and Finch et al. (2005). To test the conceptual model and proposed hypotheses, structural equation modelling with the maximum likelihood estimation method was employed using AMOS software.

\section{Results}

\section{Measurement model}

The original measurement model was designed to measure the following six constructs: intention to live healthily (INTENT), complying with guidelines (COMPLY), satisfaction with achievements (SATIS), perceived behavioral control (PBC), informational support (INFSUP) and emotional support (EMOSUP). In the final model, the last two constructs were combined under a second-order factor, i.e. social support (SOCSUP). The second-order model was chosen to improve the model's simplicity, which is supported by previous research (e.g. Ballantine and Stephenson, 2011; Hwang et al., 2010) showing that informational and emotional support are two dimensions of social support. The second-order factor construct was found to be valid as the informational support and emotional support constructs showed good internal reliability (CR 0.950 and 0.958 ) and converged well on the second-order social support factor construct (component loadings INFSUP 0.848 and EMOSUP 0.929). The model fit 
Table 2 Latent construct factor loadings

\begin{tabular}{|c|c|c|}
\hline Construct & Indicator & Loadings \\
\hline Intention to live healthily & I intend to continue to make healthy life choices in the future & 0.933 \\
\hline \multirow[t]{3}{*}{ (INTENT) } & I want to continue to make healthy life choices in the future & 0.751 \\
\hline & I intend to continue to eat a healthy diet in the future & 0.885 \\
\hline & I intend to continue to be physically active in the future & 0.629 \\
\hline \multirow[t]{3}{*}{ Compliance with guidelines (COMPLY) } & I have followed the guidelines given & 0.882 \\
\hline & I have not slipped up during the training period & 0.846 \\
\hline & I have followed the guidelines on what to eat & 0.882 \\
\hline \multirow[t]{3}{*}{ Satisfaction with achievements (SATIS) } & I have achieved the goals that I set for this program & 0.877 \\
\hline & I am satisfied with the attained results & 0.915 \\
\hline & I obtained the desired outcomes from the program & 0.799 \\
\hline \multirow[t]{3}{*}{ Perceived behavioral control (PBC) } & How confident are you that you could eat a healthy diet if you wanted to? & 0.794 \\
\hline & How much control do you feel you would have overeating a healthy diet? & 0.641 \\
\hline & How easy or difficult do you think it would be for you to follow healthy life choices in the future? & 0.780 \\
\hline \multirow[t]{2}{*}{ Social support (SOCSUP) } & Emotional support & 0.929 \\
\hline & Informational support & 0.848 \\
\hline \multirow[t]{6}{*}{ Informational support (INFSUP) } & I receive information on how I should eat and exercise from other members & 0.893 \\
\hline & I receive valuable information from other members & 0.885 \\
\hline & Other members help me understand which foods I should and should not be eating to lose weight & 0.838 \\
\hline & If I have a question related to losing weight, I can usually find answers from other members & 0.825 \\
\hline & The information from other members helps me plan my own actions better & 0.897 \\
\hline & I receive good tips on how to lose weight from other users & 0.896 \\
\hline \multirow[t]{8}{*}{ Emotional support (EMOSUP) } & I believe that other members care for me & 0.886 \\
\hline & Other members make me feel important & 0.894 \\
\hline & I feel accepted by other members & 0.784 \\
\hline & I am comforted by other members when I am disappointed with my weight loss outcomes & 0.921 \\
\hline & When I want to express my feelings related to the process, I want to share them with other members & 0.915 \\
\hline & Other members of this program encourage me to lose weight & 0.786 \\
\hline & Other members are sympathetic toward me & 0.862 \\
\hline & Seeing the success of other members helps me stay on my weight loss program & 0.830 \\
\hline Relative weight loss ( $\triangle B M I)$ & Weight loss percentage & n.a. \\
\hline \multicolumn{3}{|c|}{ Note: Loadings = standardized factor loadings } \\
\hline
\end{tabular}

of the second-order factor was also examined and found to show an acceptable fit $\left(\chi^{2}(75)=231.57, \mathrm{CMIN} / \mathrm{DF}=3.09\right.$, $\mathrm{IFI}=0.979, \mathrm{TLI}=0.974, \mathrm{RFI}=0.963, \mathrm{CFI}=0.979$ and RMSEA $=0.065$ ).

The validity of the measurement model and the unidimensionality of the constructed scales was tested with a confirmatory factor analysis (CFA). The results of the reliability and validity of the measurement scales (in Tables II and III) show that all component loadings were equal to or greater than 0.629 and that the composite reliabilities ranged from 0.78 to 0.90 , thus demonstrating good internal reliability (Bagozzi and Yi, 2012). The items were also found to converge on their assigned factors as the average variance extracted (AVE) values exceeded the cut-off value of 0.50 . The measurement model was also tested for discriminant validity using Fornell and Lacker's AVE (Fornell and Lacker, 1981) method and Bagozzi's method (Bagozzi, 1991). The correlations between the constructs were below 0.70 and thus the square roots of the AVEs showed acceptable discriminant validity. Bagozzi's method yielded similar results, further confirming the discriminant validity of the measurement model. In this approach, the Chi-square values of the unconstrained model and a model with a constraint on a pair of two latent constructs are compared. If the constrained model is significantly worse than the unconstrained model, discriminant validity is achieved. The construct-level inspection revealed that the discriminant validity of COMPLY and SATIS was not verified. However, the chi-square difference test showed that the constrained model performed the same as the unconstrained model, suggesting that the two constructs did not differ. Thus, the constructs were considered distinct as the between-factor correlation was below 0.7 and they passed Fornell-Lacker's test.

Finally, survey studies are always subject to common method bias (CMB). In the present study, $\mathrm{CMB}$ was minimized by carefully designing the questionnaire. To exclude the possibility that $\mathrm{CMB}$ could interfere with the results, a common latent factor (CLF) test (Podsakoff et al., 2003) was conducted. The results of the CLF test show that CMB is unlikely an issue because the average method-based variance was 0.043 .

\section{Structural model}

The results of testing the structural model are shown in Figure 2. The model fit was assessed through several indices, which suggested a good fit despite the high chi-square value (Schermelleh-Engel et al., 2003). The values of IFI, TLI, RFI and CFI were clearly above 0.9 and ranged from 0.932 to 0.966; the value of RMSEA was 0.05 ; and the value of CMIN/ 
Table 3 Validity, reliabilities, and intercorrelations

\begin{tabular}{lccccccr}
\hline & CR & AVE & SOCSUP & INTENT & SATIS & PBC & FOLLOW \\
\hline SOCSUP ${ }^{1}$ & 0.883 & 0.791 & 0.889 & & & & \\
INTENT & 0.881 & 0.653 & 0.235 & 0.808 & & & \\
SATIS & 0.899 & 0.748 & 0.243 & 0.432 & 0.865 & & \\
PBC & 0.784 & 0.550 & 0.174 & 0.632 & 0.476 & 0.742 & \\
COMPLY & 0.903 & 0.757 & 0.245 & 0.522 & 0.626 & 0.526 & 0.870 \\
SBMI & n.a. & n.a. & 0.035 & 0.226 & 0.619 & 0.243 & 0.449
\end{tabular}

Notes: Composite Reliability (CR), Average Variance Extracted (AVE), construct correlations, square root of AVEs (on the diagonal); Social support (SOCSUP), intention to live healthily (INTENT), satisfaction with achievements (SATIS), perceived behavioural control (PBC), compliance with guidelines (COMPLY), relative weight loss $(\triangle \mathrm{BMI}){ }_{i}^{1}$ Composed of informational support $(C R=0.950)$ and emotional support $(C R=0.958)$ dimensions.

Figure 2 Research model

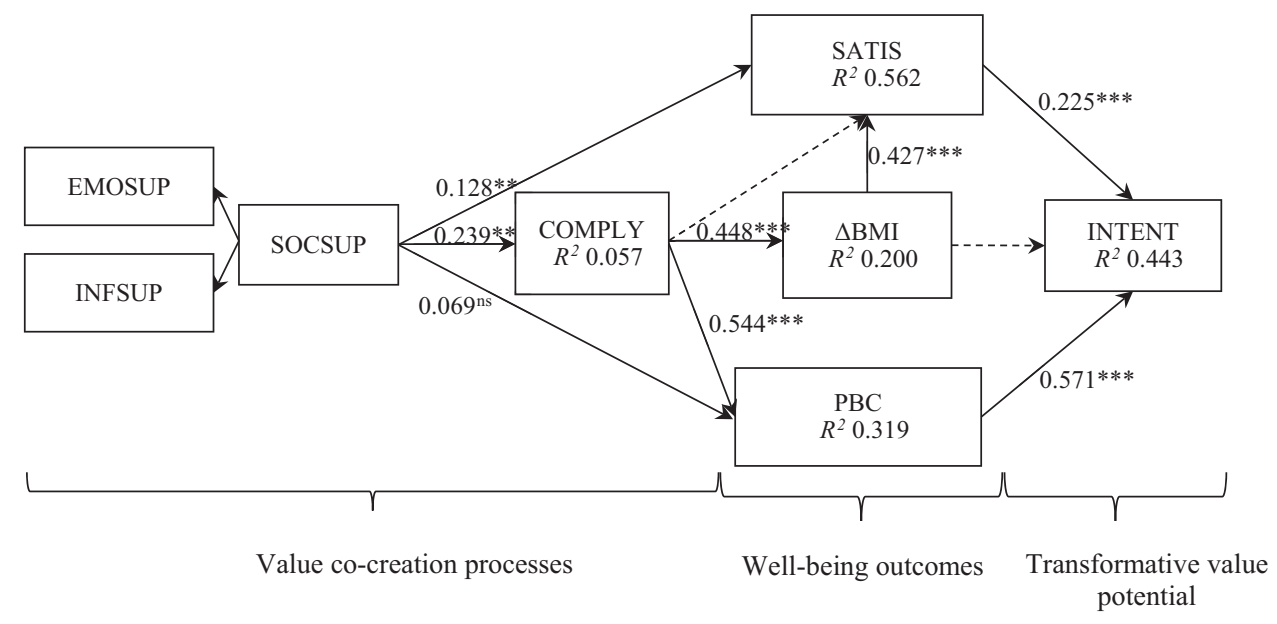

Notes: $* * * p<0.001, * * p<0.01, * p<0.05$; dashed arrows remark mediated effects presented in Table 4; Model fit: $\chi^{2}(338)=749.99 ; \mathrm{CMIN} / \mathrm{DF}=2.219$; IFI $=0.966 ; \mathrm{TLI}=0.961 ; \mathrm{RFI}=0.932$; $\mathrm{CFI}=0.965 ; \mathrm{RMSEA}=0.050$

DF was clearly below the cut-off value (Hair et al., 2014; Hu and Bentler, 1999).

The conceptual model tested with the sample of individuals participating in the online weight loss program accounted for $44 \%$ of the variance in intention to live healthily (INTENT), 56\% of the variance in satisfaction with achievement (SATIS), 32\% of the variance in perceived behavioral control (PBC), $20 \%$ of the variance in relative weight loss $(\triangle \mathrm{BMI})$ and $6 \%$ of the variance in complying with guidelines (COMPLY). The results also supported nearly all proposed hypotheses. As hypothesized, PBC $(H 1: \beta=0.571, p<0.001)$ and SATIS (H2: $\beta=$ $0.225, p<0.001$ ) were positively related to the intention to maintain healthy behavior in the future. Furthermore, PBC seemed to be a stronger driver of the intention to maintain the behavior.

$\triangle \mathrm{BMI}$ had a positive direct effect on satisfaction with achievements $(\beta=0.427, p<0.001)$ but no such direct effect on the intention to live healthily $(\beta=-0.048, p>0.05)$. However, $\triangle \mathrm{BMI}$ was expected to be indirectly related to INTENT through SATIS (H3). The results of the indirect effect analysis performed using the bias-corrected percentile bootstrapping method are shown in Table 4. The results supported the hypothesis as $\triangle \mathrm{BMI}$ had a significant positive indirect effect on the intention to maintain the learned behavior ( $\beta=0.095$, LLCI $0.041 /$ ULCI 0.158$)$. Although $\Delta \mathrm{BMI}$ had no direct effect on the intention to maintain the healthy behavior, it was found to play an important role in providing satisfaction with performance ( $\beta=0.427, p<0.001)$ and, thus, providing motivation to maintain the new behavior.

Related to H4, COMPLY had positive direct effects on $\triangle \mathrm{BMI}(\beta=0.448, p<0.001)$ and SATIS $(\beta=0.412$, $p<0.001)$. Furthermore, COMPLY was expected to have a mediation effect on SATIS via $\triangle \mathrm{BMI}$. The mediation effect was confirmed by a bootstrapping analysis with the biascorrected percentile method as shown in Table 4. When relative weight loss was not included, the direct effect of complying with guidelines on satisfaction with achievements ( $\beta=0.438, p<0.001$ ) was higher than that when relative weight loss was included as a mediator in the model $(\beta=$ $0.412, p<0.001)$. Second, the bias-corrected percentile method confirmed the indirect relationship. The indirect effect of complying with guidelines on satisfaction through relative weight loss was $\beta=0.191$ (LLCI $0.152 /$ ULCI 0.236). 
Table 4 Indirect and direct effects of relative weight loss and complying with guidelines

\begin{tabular}{|c|c|c|c|c|c|}
\hline & \multicolumn{3}{|c|}{ Indirect effects } & \multicolumn{2}{|c|}{ Direct effects } \\
\hline & $\beta$ & S.E. & LLCI/ULCI & $\beta$ & S.E. \\
\hline$\overline{C O M P L Y} \rightarrow \triangle B M I$ & & & & $0.448^{* * *}$ & 0.040 \\
\hline$\triangle B M I \rightarrow S A T I S$ & & & & $0.427^{* * *}$ & 0.041 \\
\hline COMPLY $\rightarrow$ SATIS & $0.191^{* *}$ & 0.021 & $0.152 / 0.236$ & $0.412^{* * *}$ & 0.053 \\
\hline SATIS $\rightarrow$ INTENT & & & & $0.222^{* * *}$ & 0.065 \\
\hline$\triangle B M I \rightarrow I N T E N T$ & $0.095^{* *}$ & 0.029 & $0.041 / 0.158$ & $-0.048 \mathrm{~ns}$ & 0.049 \\
\hline
\end{tabular}

Therefore, $\triangle \mathrm{BMI}$ was found to mediate the relationship between COMPLY and SATIS (H4).

Finally, complying with guidelines had a positive direct effect on PBC ( $\beta=0.544, p=0.001)$ as hypothesized (H5). Furthermore, social support had a positive effect on complying with guidelines $(\beta=239, p<0.01)$ and satisfaction with achievements $(\beta=0.128, p<0.01)$ but no direct effect on perceived behavioral control $(\beta=0.069, p>0.05)$. Therefore, $H 6$ and $H 7$ were supported, but $H 8$ was not supported.

\section{Discussion}

\section{Theoretical implications}

In this study, we focused on exploring how online weight loss services can successfully fulfill their transformative value potential and reinforce an uplifting, durable change among their customers. Building upon the TSR literature (Mulder et al., 2015; Blocker and Barrios, 2015), we argued that the true transformative value creation potential of services is realized not only as the temporally improved well-being of service customers but when customers intend to continue to maintain their improved well-being after the service process.

The results of this study indicate that the eudaimonic wellbeing outcomes of online weight loss services and customers' intention to continue to live healthily in the future are interrelated. The findings imply that PBC acts as a strong predictor of customers' intentions to maintain a healthy lifestyle (Rothman, 2000). The findings also highlight the significant role of satisfaction with achievements in inspiring the future intention to live healthily (Baldwin et al., 2006). The relevance of these findings for the TSR literature lies in the idea that positive evaluations of one's improved well-being allow durable behavioral change to continue. While it is crucial for customers to maintain behavioral change, it is as important for customers to be motivated to continue to maintain the behavior. These results support the importance of PBC, self-efficacy and customers' sense of achievements for transformative services (Sharma et al., 2017). These findings also collectively contribute to the TSR literature by showing that improvements in customers' eudaimonic well-being are key for transformative services to facilitate durable change among their customers (Blocker and Barrios, 2015).

Weight loss is the central short-term aim of online weight loss service participants. However, weight loss alone was found inconclusive in reaching the transformational value potential. This finding supports earlier evidence indicating that the amount of weight loss is inadequate in explaining the maintenance of the changed weight (Montani et al., 2015).
However, weight loss still plays an indirect role in reinforcing the transformational value potential of weight loss services. Based on the results of this study, this process requires customers to be satisfied with their weight loss process and achieved results. This result again supports the need to emphasize the subjective well-being outcomes of transformative services to enable a durable change.

The findings also support the existing TSR literature (Sharma et al., 2017; Abney et al., 2017; Black and Gallan, 2015 ) by showing the relevance of value co-creation among different actors in the service network (in this study, customers, the service provider and peer customers) to the well-being of service customers. Successful compliance with eating/ exercising guidelines was found to be important for increasing customers' PBC and satisfaction with achievements. Thus, successful compliance improves customers' confidence in their capabilities and control over their healthy lifestyle choices. This finding supports the role of compliance in strengthening the eudaimonic well-being outcomes of transformative services (Sharma et al., 2017). Similarly, compliance seems to be directly related to satisfaction with achievements. This finding implies that customers may evaluate their successful efforts to comply with guidelines as satisfying. Moreover, compliance further allows customers to achieve their weight loss aims, which helps increase their subjective well-being. These findings support the key role of compliance in health service contexts (Dellande et al., 2004).

In this study, social support was shown to act as another resource for value co-creation. Social support was found to help customers comply with guidelines and increased their satisfaction with their achievements. These findings are logical as social support helps customers perform better and cope with their disappointments (Hwang et al., 2010). Interestingly, social support was not found to have a direct effect on PBC. The reason for this result might be that PBC builds on individuals' past performances (Ajzen, 1991). In line with this argument, the findings of this current study indicate that social support helps customers to comply with the guidelines, which increases their PBC. This finding supplements the previous research (Oh et al., 2013; Parkinson et al., 2019), which suggests that social support and self-efficacy/PBC are directly linked.

The results of this current study collectively provide encouraging information regarding the role of eating/exercising guidelines and social support as resources in transformative value co-creation and help online weight loss services fulfill their transformative value potential through the improved eudaimonic well-being of its customers. 


\section{Managerial implications}

When online weight loss service providers adopt a transformative service perspective, they should help customers realize their full potential in managing sustainable weight loss and maintaining a healthy lifestyle. Therefore, service providers need to apply a genuine customer-centric mentality to their services. Thus, service providers should focus not only on the amount of weight loss their customers can achieve during the service period but also on their customers' subjective well-being outcomes achieved through the service. The following implications of this study are aspired to help weight loss service managers adopt a transformative service perspective and reinforce the transformative value potential of their services.

First, service providers should extend their perspective beyond the weight loss service period and weight loss as the only outcome. Managing services aiming to achieve sustainable change must also make their customers feel empowered and help them act according to the requirements of maintaining a healthy lifestyle after the service period. In particular, service managers might aim to provide skills and knowledge that help customers be in control of continuing to maintain the new behavior in the future. Thus, the knowledge and skill development should fit customers' everyday lives. The farther the required behavior is from normal life and the more effort is required to maintain a healthy lifestyle, the less likely the behavior is to be continued. For example, one-sided soup diets or the strict counting of calories are hardly sustainable activities, thus questioning the transformative value potential of these actions. In contrast, providing guidance regarding good basic food ingredients, easy recipes and versatile healthy eating in general might be especially helpful for maintaining the behavior.

Second, service providers should help customers to explicitly recognize their successes related to their weight loss process and related positive emotional responses. In doing so, service providers need to go beyond asking customers to measure how much they have lost weight during the service period. Instead, service providers could assign their customers a simple exercise, where customers could reflect their weight loss journey. The exercise could include queries related to what customers have learned during the process, what they have found easy to carry out and which things they have found pleasurable and satisfying. The exercise could also include question related to things that motivate or act as barriers for continuing the healthier lifestyle. This kind of reflective exercise might help customers to recognize their improved well-being beyond the improved body mass indexes and assist customers to orientate toward maintaining the improved well-being.

Third, establishing a social support group has a great potential for online weight loss services. Social support groups help customers to comply with guidelines and increase their performance, thus nurturing satisfaction with achievements. These groups also have the potential to help customers balance the disappointments experienced during the weight loss service process.

Finally, considering private weight loss services, the adoption of the transformative view does not indicate that services must be purchased only once. Focusing on service models that enable customers to advance their knowledge and learn new ways of living healthily might motivate their further engagement with service providers and lead to repurchases. Repurchasing customers could also be a valuable source of social support to others as they have already gained the knowledge and skills necessary to make healthy lifestyle choices.

\section{Limitations and future research}

This study addressed the transformational value potential of weight loss services. The intention to continue to live a healthy lifestyle is a functional concept representing customer's orientation toward a durable change. Intention is also a measure that service providers are able to monitor at the end of the service process. However, intentions do not always accurately explain actual behavior, leading to the main limitation of this study. This study is unable to verify the relationship between the transformative value potential of services and durable transformation. In the future, longitudinal data are desirable to verify the roles of different well-being outcomes (including satisfaction with achievements and PBC) in actual durable maintenance behavior in short and long timeframes.

In this study, most respondents were women, which can be considered a limitation. For example, some results (such as those related to social support) may be gender-related, which can decrease the generalizability of the findings to all consumers. Future research could gather and compare samples from both genders and test the constructed model to detect gender differences. In addition, this study focuses on the interaction occurring within the service only without considering other actors who may have an impact on individual well-being and the maintenance of healthy lifestyle (e.g. families and friends). Moreover, this study addressed the transformative value potential of services at the individual level without considering the communal or societal benefits emerging from the transformative value potential of weight loss services. Future research could attempt to address these issues.

Furthermore, future research should continue to reveal the transformative potential of different types of services (Rosenbaum et al., 2011).

\section{Note}

1 In the text, SE and PBC are used interchangeably in reference to the term used in the original publication.

\section{References}

Abney, A.K., White, A., Shanahan, K.J. and Locander, W.B. (2017), "In their shoes: co-creating value from deaf/hearing perspectives", Fournal of Services Marketing, Vol. 31 Nos 4/5, pp. 313-332.

Ajzen, I. (1991), "The theory of planned behavior", Organizational Behavior and Human Decision Processes, Vol. 50 No. 2, pp. 179-211.

Ajzen, I. (2002), "Perceived behavioral control, selfefficacy, locus of control, and the theory of planned behaviour", Fournal of Applied Social Psychology, Vol. 32 No. 4, pp. 665-683. 
Ajzen, I. and Fishbein, M. (1980), Understanding Attitudes and Predicting Social Behaviour, Prentice-Hall, Englewood Cliffs, NJ.

Anderson, L. and Ostrom, A.L. (2015), "Transformative service research: advancing our knowledge about service and well-being", fournal of Service Research, Vol. 18 No. 3, pp. 243-249.

Anderson, L., Ostrom, A.L. and Bitner, M.J. (2011), "Surrounded by services: a new lens for examining the influence of services as social structures on well-being", working paper, W.P. Carey School of Business, AZ State University.

Anderson, L., Ostrom, A.L., Corus, C., Fisk, R.P., Gallan, A.S., Giraldo, M., Mende, M., Mulder, M., Rayburn, S. W., Rosenbaum, M.S., Shirahada, K. and Williams, J.D. (2013), "Transformative service research: an agenda for the future", Fournal of Business Research, Vol. 66 No. 8, pp. 1203-1210.

Bagozzi, R.P. (1991), "Further thoughts on the validity of measures of elation, gladness, and joy", fournal of Personality and Social Psychology, Vol. 61 No. 1, pp. 98-104.

Bagozzi, R.P. and Yi, Y. (2012), "Specification, evaluation, and interpretation of structural equation models", fournal of the Academy of Marketing Science, Vol. 40 No. 1, pp. 8-34.

Bagozzi, R.P. and Dholakia, U. (1999), "Goal setting and goal striving in consumer behaviour", fournal of Marketing, Vol. 63 No. 4_suppl1, pp. 19-32.

Baldwin, A.S., Rothman, A.J. and Jeffery, R.W. (2009), "Satisfaction with weight loss: examining the longitudinal covariation between people's weight-loss-related outcomes and experiences and their satisfaction", Annals of Behavioral Medicine, Vol. 38 No. 3, pp. 213-224.

Baldwin, A.S., Rothman, A.J., Hertel, A.W., Linde, J.A., Jeffery, R.W., Finch, E.A. and Lando, H.A. (2006), "Specifying the determinants of the initiation and maintenance of behavior change: an examination of selfefficacy, satisfaction, and smoking cessation", Health Psychology, Vol. 25 No. 5, pp. 626-634.

Ballantine, P.W. and Stephenson, R.J. (2011), "Help me, I'm fat! social support in online weight loss networks", fournal of Consumer Behaviour, Vol. 10 No. 6, pp. 332-337.

Bandura, A. (1986), "The explanatory and predictive scope of self-efficacy theory", fournal of Social and Clinical Psychology, Vol. 4 No. 3, pp. 359-373.

Bandura, A. (1993), "Perceived self-efficacy in cognitive development and functioning", Educational Psychologist, Vol. 28 No. 2, pp. 117-148.

Bandura, A. (2004), "Social cognitive theory for personal and social change by enabling media", in. Singhal, A., Rogers, E. M., Sabido, M. and Cody, M.J. (Eds), EntertainmentEducation and Social Change: History, Research, and Practice, Lawrence Erlbaum, Mahwah, NJ, pp. 75-96.

Black, H.G. and Gallan, A.S. (2015), "Transformative service networks: cocreated value as well-being", The Service Industries Fournal, Vol. 35 Nos 15/16, pp. 826-845.

Blocker, C.P. and Barrios, A. (2015), "The transformative value of a service experience", Fournal of Service Research, Vol. 18 No. 3, pp. 265-283.

Chan, K.W., Yim, C.K. and Lam, S.S. (2010), "Is customer participation in value creation a double-edged sword? Evidence from professional financial services across cultures", fournal of Marketing, Vol. 74 No. 3, pp. 48-64.

Chandler, J.D. and Lusch, R.F. (2015), "Service systems: a broadened framework and research agenda on value propositions, engagement, and service experience", fournal of Service Research, Vol. 18 No. 1, pp. 6-22.

Deci, E.L. and Ryan, R.M. (2000), "The 'what' and 'why' of goal pursuits: human needs and the self-determination of behavior", Psychological Inquiry, Vol. 11 No. 4, pp. 227-268.

Dellande, S., Gilly, M.C. and Graham, J.L. (2004), “Gaining compliance and losing weight: the role of the service provider in health care services", fournal of Marketing, Vol. 68 No. 3, pp. 78-91.

DiClemente, C.C., Prochaska, J.O. and Gibertini, M. (1985), "Self-efficacy and the stages of self-change of smoking”, Cognitive Therapy and Research, Vol. 9 No. 2, pp. 181-200.

Diener, E., Wirtz, D., Tov, W., Kim-Prieto, C., Choi, D.W., Oishi, S. and Biswas-Diener, R. (2010), "New well-being measures: short scales to assess flourishing and positive and negative feelings", Social Indicators Research, Vol. 97 No. 2, pp. 143-156.

Dombrowski, S.U., Knittle, K., Avenell, A., Araújo-Soares, V. and Sniehotta, F.F. (2014), "Long term maintenance of weight loss with non-surgical interventions in obese adults: systematic review and meta-analyses of randomised controlled trials", BMF, Vol. 348.

Elfhag, K. and Rössner, S. (2005), "Who succeeds in maintaining weight loss? A conceptual review of factors associated with weight loss maintenance and weight regain", Obesity Reviews, Vol. 6 No. 1, pp. 67-85.

Finch, E.A., Linde, J.A., Jeffery, R.W., Rothman, A.J., King, C.M. and Levy, R.L. (2005), "The effects of outcome expectations and satisfaction on weight loss and maintenance: correlational and experimental analyses - a randomized trial", Health Psychology, Vol. 24 No. 6, pp. 608-616.

Fishbach, A., Shah, J.Y. and Kruglanski, A.W. (2004), "Emotional transfer in goal systems", fournal of Experimental Social Psychology, Vol. 40 No. 6, pp. 723-738.

Fleig, L., Lippke, S., Pomp, S. and Schwarzer, R. (2011), "Exercise maintenance after rehabilitation: how experience can make a difference", Psychology of Sport and Exercise, Vol. 12 No. 3, pp. 293-299.

Fornell, C. and Lacker, D.F. (1981), "Structural equation models with unobservable variables and measurement error: algebra and statistics", fournal of Marketing Research, Vol. 18 No. 3, pp. 382-388.

Gorin, A.A., Pinto, A.M., Tate, D.F., Raynor, H.A., Fava, J.L. and Wing, R.R. (2007), "Failure to meet weight loss expectations does not impact maintenance in successful weight losers", Obesity, Vol. 15 No. 12, pp. 3086-3090.

Hair, J., Jr, Hult, G., Ringle, C. and Sarstedt, M. (2014), A Primer on Partial Least Squares Structural Equation Modeling (PLS-SEM), Sage, Los Angeles.

Hether, H.J., Murphy, S.T. and Valente, T.W. (2014), "It's better to give than to receive: the role of social support, trust, and participation on health-related social 
networking sites", fournal of Health Communication, Vol. 19 No. 12, pp. 1424-1439.

House, J.S. (1981), Work Stress and Social Support, AddisonWesley, Reading, MA.

Hu, L.T. and Bentler, P.M. (1999), "Cutoff criteria for fit indexes in covariance structure analysis: conventional criteria versus new alternatives", Structural Equation Modeling: a Multidisciplinary fournal, Vol. 6 No. 1, pp. 1-55.

Hutchesson, M.J., Rollo, M.E., Krukowski, R., Ells, L., Harvey, J. and Morgan, P.J. (2015), "eHealth interventions for the prevention and treatment of overweight and obesity in adults: a systematic review with meta-analysis", Obesity Reviews, Vol. 16 No. 5, pp. 376-392.

Hwang, K.O., Ottenbacher, A.J., Green, A.P., Cannon-Diehl, M.R., Richardson, O., Bernstam, E.V. and Thomas, E.J. (2010), "Social support in an internet weight loss community", International fournal of Medical Informatics, Vol. 79 No. 1, pp. 5-13.

Hwang, K.O., Ottenbacher, A.J., Lucke, J.F., Etchegaray, J.M., Graham, A.L., Thomas, E.J. and Bernstam, E.V. (2011), "Measuring social support for weight loss in an internet weight loss community", Fournal of Health Communication, Vol. 16 No. 2, pp. 198-211.

Keats, M.R. and Culos-Reed, N. (2009), "A theory-driven approach to encourage physical activity in pediatric cancer survivors: a pilot study", fournal of Sport and Exercise Psychology, Vol. 31 No. 2, pp. 267-283.

Kozak, A.T., Buscemi, J., Hawkins, M.A., Wang, M.L., Breland, J.Y., Ross, K.M. and Kommu, A. (2017), "Technology-based interventions for weight management: current randomized controlled trial evidence and future directions", fournal of Behavioral Medicine, Vol. 40 No. 1, pp. 99-111.

Kuppelwieser, V.G. and Finsterwalder, J. (2016), "Transformative service research and Service-Dominant logic: quo vaditis?", foumal of Retailing and Consumer Services, Vol. 28 No. 1, pp. 91-98.

Linde, J.A., Rothman, A.J., Baldwin, A.S. and Jeffery, R.W. (2006), "The impact of self-efficacy on behavior change and weight change among overweight participants in a weight loss trial", Health Psychology, Vol. 25 No. 3, pp. 282-291.

MacLean, P.S., Higgins, J.A., Giles, E.D., Sherk, V.D. and Jackman, M.R. (2015), "The role for adipose tissue in weight regain after weight loss", Obesity Reviews, Vol. 16, pp. 45-54.

Montani, J.P., Schultz, Y. and Dulloo, A.G. (2015), "Dieting and weight cycling as risk factors for cardiometabolic diseases: who is really at risk?", Obesity Reviews, Vol. 16, pp. 7-18.

Mulder, M.R., Rapp, J.M., Hamby, A. and Weaver, T. (2015), "Consumer transformation through volunteer service experiences", The Service Industries fournal, Vol. 35 Nos 15/16, pp. 865-882.

Napolitano, M.A., Hayes, S., Bennett, G.G., Ives, A.K. and Foster, G.D. (2013), "Using Facebook and text messaging to deliver a weight loss program to college students", Obesity, Vol. 21 No. 1, pp. 25-31.

Oh, H.J., Lauckner, C., Boehmer, J., Fewins-Bliss, R. and Li, K. (2013), "Facebooking for health: an examination into the solicitation and effects of health-related social support on social networking sites", Computers in Human Behavior, Vol. 29 No. 5, pp. 2072-2080.

Parkinson, J., Mulcahy, R.F., Schuster, L. and Taiminen, H. (2019), "A transformative value co-creation framework for online services", Fournal of Service Theory and Practice, Vol. 29 No. 3, pp. 353-374.

Parkinson, J., Schuster, L., Mulcahy, R. and Taiminen, H.M. (2017), "Online support for vulnerable consumers: a safe place?”, Fournal of Services Marketing, Vol. 31 Nos 4/5, pp. 412-422.

Podsakoff, P.M., MacKenzie, S.B., Lee, J.Y. and Podsakoff, N. P. (2003), "Common method biases in behavioral research: a critical review of the literature and recommended remedies", Fournal of Applied Psychology, Vol. 88 No. 5, pp. 879-903.

Povey, R., Conner, M., Sparks, P., James, R. and Shepherd, R. (2000), "The theory of planned behaviour and healthy eating: examining additive and moderating effects of social influence variables”, Psychology \& Health, Vol. 14 No. 6, pp. 991-1006.

Previte, J. and Robertson, N. (2019), “A continuum of transformative service exchange: insights for service and social marketers", fournal of Services Marketing, Vol. 33 No. 6, pp. 671-686.

Rhodes, R.E. and de Bruijn, G.J. (2013), "How big is the physical activity intention-behaviour gap? a Metaanalysis using the action control framework", British Fournal of Health Psychology, Vol. 18 No. 2, pp. 296-309.

Rosenbaum, M., Corus, C., Ostrom, A., Anderson, L., Fisk, R., Gallan, A., Giraldo, M., Mende, M., Mulder, M., Rayburn, S.W. and Shirahada, K. (2011), "Conceptualisation and aspirations of transformative service research", fournal of Research for Consumers, Vol. 19, pp. 1-6.

Rothman, A.J. (2000), "Toward a theory-based analysis of behavioral maintenance", Health Psychology, Vol. 19 No. 1, Suppl, pp. 64-69.

Rothman, A.J., Baldwin, A.S., Hertel, A.W., and Fuglestad, P. T. (2004), "Self-regulation and behavior change: Disentangling behavioral initiation and behavioral maintenance", in Vohs, K. and Baumeister, R. (Eds). The Handbook of Self-Regulation, Guilford Press, New York, NY, pp. 130-148.

Schermelleh-Engel, K., Moosbrugger, H. and Müller, H. (2003), "Evaluating the fit of structural equation models: tests of significance and descriptive goodness-of-fit measures", Methods of Psychological Research Online, Vol. 8 No. 2, pp. 23-74.

Sharma, S., Conduit, J. and Hill, S.R. (2017), "Hedonic and Eudaimonic well-being outcomes from co-creation roles: a study of vulnerable customers", fournal of Services Marketing, Vol. 31 Nos 4/5, pp. 397-411.

Turner-McGrievy, G. and Tate, D. (2011), "Tweets, apps, and pods: results of the 6-month mobile pounds off digitally (mobile POD) randomized weight-loss intervention among adults", fournal of Medical Internet Research, Vol. 13 No. 4.

Uchino, B.N., Uno, D. and Holt-Lunstad, J. (1999), "Social support, physiological processes, and health", 
Current Directions in Psychological Science, Vol. 8 No. 5, pp. 145-148.

Vargo, S.L. and Lusch, R.F. (2004), "Evolving to a new dominant logic in marketing", fournal of Marketing, Vol. 68 No. 1, pp. 1-17.

Vargo, S.L. and Lusch, R.F. (2008), "Service-dominant logic: continuing the evolution", fournal of the Academy of Marketing Science, Vol. 36 No. 1, pp. 1-10.

Willis, E. (2014), "The making of expert patients: the role of online health communities in arthritis selfmanagement", Fournal of Health Psychology, Vol. 19 No. 12, pp. 1613-1625.
Winett, R.A., Anderson, E.S., Wojcik, J.R., Winett, S.G. and Bowden, T. (2007), "Guide to health: nutrition and physical activity outcomes of a Group-Randomized trial of an Internet-based intervention in churches", Annals of Behavioral Medicine, Vol. 33 No. 3, pp. 251-261.

Wing, R.R. and Jeffery, R.W. (1999), "Benefits of recruiting participants with friends and increasing social support for weight loss and maintenance", fournal of Consulting and Clinical Psychology, Vol. 67 No. 1, pp. 132-138.

\section{Corresponding author}

Heini Taiminen can be contacted at: Heini.taiminen@jyu.fi 